\title{
CHARACTERIZATION OF THREE BENZOATE DEGRADING ANOXYGENIC PHOTOSYNTHETIC BACTERIA ISOLATED FROM THE ENVIRONMENT
}

\author{
DWI SURYANTO ${ }^{1}$, ANTONIUS SUWANTO ${ }^{23 *}$, and ANJA MERYANDINI ${ }^{3}$ \\ ; Dept. of Biology, Faculty of Science and Mathematics, North Sumatra University, \\ Medan, Indonesia ${ }^{2}$ South East Asian Regional Center \\ for Tropical Biology (SEAMEO-BIOTROP), \\ Bogor, Indonesia \\ ${ }^{3}$ Dept. of Biology, Faculty of Science and Mathematics, Bogor Agricultural University, \\ Bogor, Indonesia
}

\begin{abstract}
Three anoxygenic photosynthetic bacteria, DS-1, DS-4 and Cas-13, have been examinated for their morphological and physiological properties. All strains were rod-shape cells with a swollen terminal end, Gram negative, motile, non-halophilic, non-alkalophilic and non-acidophilic, and capable of utilizing benzoate aerobically and photo-anaerobically. Sequence analysis of part of 16S rRNA genes showed that DS1 and Cas-13 were closely related to Rhodopseudomonas palustris Strain 7 with a similarity of $97 \%$, whereas DS-4 may not be closely related to the former two strains with a similarity of $78 \%$ based on the constructed phylogenic tree. Spectral analysis indicated that the three bacteria had bacteriochlorophyl $a$ and normal spirilloxanthin series.

Growth in medium enriched with vitamin and supplemented with benzoate as their sole C-sources was better than in medium without vitamin. Benzoate degradation in medium with vitamin was accelerated. The ability to grow on benzoate without added vitamins indicated that the bacteria were able to synthesize their own vitamins.
\end{abstract}

Key words: anoxygenic photosynthetic bacteria/ benzoate degradation/ 16S rRNA gene.

\section{INTRODUCTION}

Some toxic compounds are slowly degraded in polluted aerobic zones and, therefore, may leach into anaerobic subsurface environments (Kohring et al. 1989). Anaerobic degradation of such compounds may play an important role in eliminating toxic substances. Anaerobic bioremediation has been proposed as an inexpensive method for in situ removal of organic contaminants in the environment (Kuo and Genthner 1996). Recent concern about the environmental fate of industrially produced organic compounds has prompted a resurgence of interest in the anaerobic degradation of aromatic compounds (Harwood and Gibson 1988).

Anoxygenic photosynthetic bacteria (APB) are nutritionally versatile in their ability to utilize diverse sources of carbon ranging from simple aliphatic organic acids to complex polysaccharides (Hiraishi et al. 1995). The occurrence of these bacteria as common inhabitants in aquatic and some terrestrial habitats in nature

' Corresponding author: e-mail address : asuwanto@indo.net.id 
(Hiraishi et al. 1995) might be explained partly by the fact that these bacteria survive on various modes of energy-generating systems (Hiraishi et al. 1995). The ability of phototrophic purple non-sulfur bacteria to grow aerobically and anaerobically in the presence of diverse aromatic compounds makes these good candidates for potential biodegradation of harmful compounds (Hanvood and Gibson 1988; Wright and Madigan 1991; Shoreit and Shaheb 1994). Commercialization of these bacteria for purification treatment plants was initiated about 15 years ago (Kobayashi and Kobayashi 1995).

Not many phototrophic purple non-sulfur bacteria species are known to degrade aromatic compounds. Rhodopseudomonas palustris (Harwood and Gibson 1988; Gibson and Gibson 1992; Shoreit and Shaheb 1994), Rhodomicrobium vannielii (Wright and Madigan 1991), Rhodobacter capsulatus (Blasco and Castillo 1992; Shoreit and Shaheb 1994), Rs. blastica, and Rhodospirilium rubrum (Shoreit and Shaheb 1994) are able to degrade a variety of monocyclic aromatic compounds with or without other C-sources.

Benzoate and its derivatives are among the common aromatic compounds that can be completely mineralized (Harwood and Gibson 1988; Wright and Madigan 1991; Shoreit and Shaheb 1994). However, Blasco and Castillo (1992) noted that Rhodobacter capsulatus E1F1 is able to degrade mononitrophenol and dinitrophenol with acetate as its carbon source. Rs. palustris utilized several phenolic compounds, hydroxylated and methoxylated aromatic acids, aromatic aldehydes, and hydroaromatic acids (Harwood and Gibson 1988). Other diverse aromatic compounds have also been reported to be utilized by this group (Harwood and Gibson 1988; Wright and Madigan 1991; Shoreit and Shaheb 1994).

Degradation of aromatic compound by phototrophic purple non-sulfur bacteria in general was emphasized in this investigation based on their ability to utilize diverse aromatic compounds. To date, this group of bacteria has not been subjected to intensive examination (Harwood and Gibson 1988). This study focused on the ability of three new isolates of APB to utilize benzoate. Identification of the bacterial isolates based on their 16S-rRNA genes as well as their morphological and physiological properties was also carried out.

\section{MATERIALS AND METHODS}

\section{Bacterial cultures and cultivation}

Three isolates of APB, designated as DS-1, DS-4, and Cas-13 were studied. The two former strains were isolated from Java, and the last was isolated from Moluccas. All isolates were maintained on modified Sistrom medium with benzoate as the sole carbon source.

To determine the ability of the bacteria to utilize and degrade aromatic compounds, the isolates were grown in modified Sistrom by omitting all carbon sources, including nitrilo-triacetic acid, supplemented with $5 \mathrm{mM}$ benzoate as the C- 
source with or without vitamins in $100 \mathrm{ml}$ completely filled screw-capped tubes. Isolates also were grown in modified Sistrom supplemented with vitamins and 5 $\mathrm{mM}$ succinate, or $5 \mathrm{mM}$ acetate as their carbon sources to serve as a means of comparison.

For cultures grown on benzoate, the inocula were obtained from 3-day old cultures of bacteria grown in modified Sistrom with benzoate with an initial cell number of $5 \times 10^{6}$ cells $/ \mathrm{ml}$. For cultures to test other C-sources, inocula were taken from 2-day old cultures grown in Sistrom media with succinate as C-source. Unless mentioned otherwise, all media were adjusted to $\mathrm{pH}$ 7.2.

\section{Growth condition, measurement of growth, and quantitation of benzoate}

Cultures were illuminated with a $40 \mathrm{~W}$ tungsten bulb at a distance of $30 \mathrm{~cm}$. Growth rates were determined by measuring turbidity at $660 \mathrm{~nm}$ every 24 hours. For cultures grown in $5 \mathrm{mM}$ succinate and $5 \mathrm{mM}$ acetate, growth rates were measured every 12 hours. For cultures grown in benzoate, residual benzoate levels were measured at 120 hours of incubation. Benzoate concentration was measured at $276 \mathrm{~nm}$ using a Hitachi Model U-2010 UV/Vis spectrophotometer (Hitachi Instrument, Inc. Japan) according to Shoreit and Shabeb (1994). Cell density of the isolates grown in other C-sources was measured after 72 hours of inoculation.

\section{Spectral analysis}

Cells were harvested from 7-day old anaerob-phototrophic cultures grown on modified Sistrom supplemented with vitamins and $5 \mathrm{mM}$ succinate as sole carbon source, and suspended in ICM buffer (10 mM phosphate buffer $\mathrm{pH} 7.0$ and $1 \mathrm{mM} \mathrm{Na}$ EDTA pH 7.0). Sonication was carried out using Soniprep 150 (MSB, UK) at an amplitude of $2 \mathrm{u}$. for 2 minutes, three times with a time interval of 1 minute. Cell extracts were centrifuged at $3000 \mathrm{rpm}$ for 30 minutes at $4^{\circ} \mathrm{C}$. Protein concentration was determined according to the Pierce BCA* Protein Assay Kit (Rockford, III, USA). Spectral analysis was performed using Hitachi U-2010 in protein concentration of \pm 100 (ig/ml.

\section{Amplification and sequencing of part of 16S rRNA genes}

To sequence part of the 16S-rRNA genes, the 16S-rRNA genes were amplified by PCR using specific primers of 63f and 1387r from genomic DNA (200 ng) on ReadyTo-GO PCR Beads (Pharmacia-Biotech, Uppsala, Sweden). Phenol-chloroformisoamylalcohol (25:24:1) treatment, ethanol precipitation, and agarose gel electrophoresis were used to purify the genomic DNA. Total volume of the PCR reaction (25 ul) consisted of $1.5 \mathrm{U}$ Tag DNA Polymerase, lOmM Tris-HCl (pH 9 at room temperature), $50 \mathrm{mM} \mathrm{KC1,} 1.5 \mathrm{mM} \mathrm{MgCl}$, $200 \mathrm{uM}$ of each dNTPs and stabilizer including BSA. The reaction was incubated in a Gene Amp PCR System 2400 Thermocycler (Perkin-Elmer Cetus, Norwalk, Conn.). 
Part of 16S-rRNA gene was sequenced to infer the closest related organism from the Ribosomal Database Project (RDP) maintained at the University of Illinois, Urbana-Champaign. The sequencing reactions were done by using the Big Dye Ready Reaction Dye Deoxy Terminator kit, purified by ethanol-sodium acetate precipitation. The reactions were run on an ABI PRISM 377 DNA Sequencer (PE Applied Biosystems, Foster City, CA.).

\section{Construction of phylogenetic trees}

For the construction of phylogenetic trees, cluster analysis of 16S-rRNA gene was done by a computer program from the European Bioinformatics Institute (http://www.ebi.ac.uk). The Treecon computer program (Yves Van de Peer of the Department of Biochemistry, University of Antwerp) was used to determine their phylogenetic relatedness based on their nucleotide sequences and MFLP profiles obtained from pulsed-field gel electrophoresis.

\section{RESULTS AND DISCUSSION}

The three new isolates described in this study were similar in their morphological properties. All were Gram negative, non-halophilic, non-alkali or acidophilic, aerobic and anaerob-phototrophs that have motile rod-shaped cells with terminal swellings. Under anaerobic photothrophic growth conditions, all new isolates produced brick-red and pink cultures in succinate and benzoate, respectively.

Spectral analysis of cell free extracts (Figure 1) of photosynthetic pigments showed absorption maxima for DS-1 at 374, 493, 587, 803 and $852 \mathrm{~nm}$, DS-4 at 371, 501, 585, 803 and $848 \mathrm{~nm}$, and Cas-13 at 373, 502, 585, 802 and $871 \mathrm{~nm}$ indicating the presence of bacteriochlorophyl $a$ and normal spirilloxanthin series including lycopene and rhodopin (Imhoff 1995). In this respect, the three isolates were nearly identical to each other and might be considered as one group. However, these isolates clearly differed from Rhodobacter sphaeroides 2.4.1., which has different absorption maxima (376, 451, 453, 477, 507, 587, 746, 799, and $850 \mathrm{~nm}$ ), with yellow-brown colonies grown anaerobically in succinate.

The results from the analysis of partial sequencing of 16S-rRNA (c.a. 500 bp) of DS-4, DS-1, and Cas-13 demonstrated that DS-4 and Cas-13 were closely related (Figure 2). Partial sequencing of the first $500 \mathrm{bp}$ of $16 \mathrm{~S}$ rRNA gene could lead to a main line of descent (Stackebrandt and Rainey 1995).

Comparison with the RDP database of the University of Illinois indicated that both DS-1 and Cas-13 demonstrated 97\% similarity with Rs. palustris Strain 7, and of $83 \%$ and $84 \%$ with $R b$. sphaeroides IL106, respectively (Table 1). Similarity of those of DS-4 to Rs. palustris Strain 7 was 78\%. These results suggested that DS-1 and Cas13 are likely to be one species, Rs. palustris. DS-4, however, is significantly different from DS-1 and Cas-13 by 22\%, and from $R b$. sphaeroides IL106 by 30\%. Complete sequence analysis is needed to give more definitive information about the taxonomic position of these three isolates. 
Characterization of three benzoate degrading anoxygenic photosynthetic bacteria -Dwi Suryanto et al.
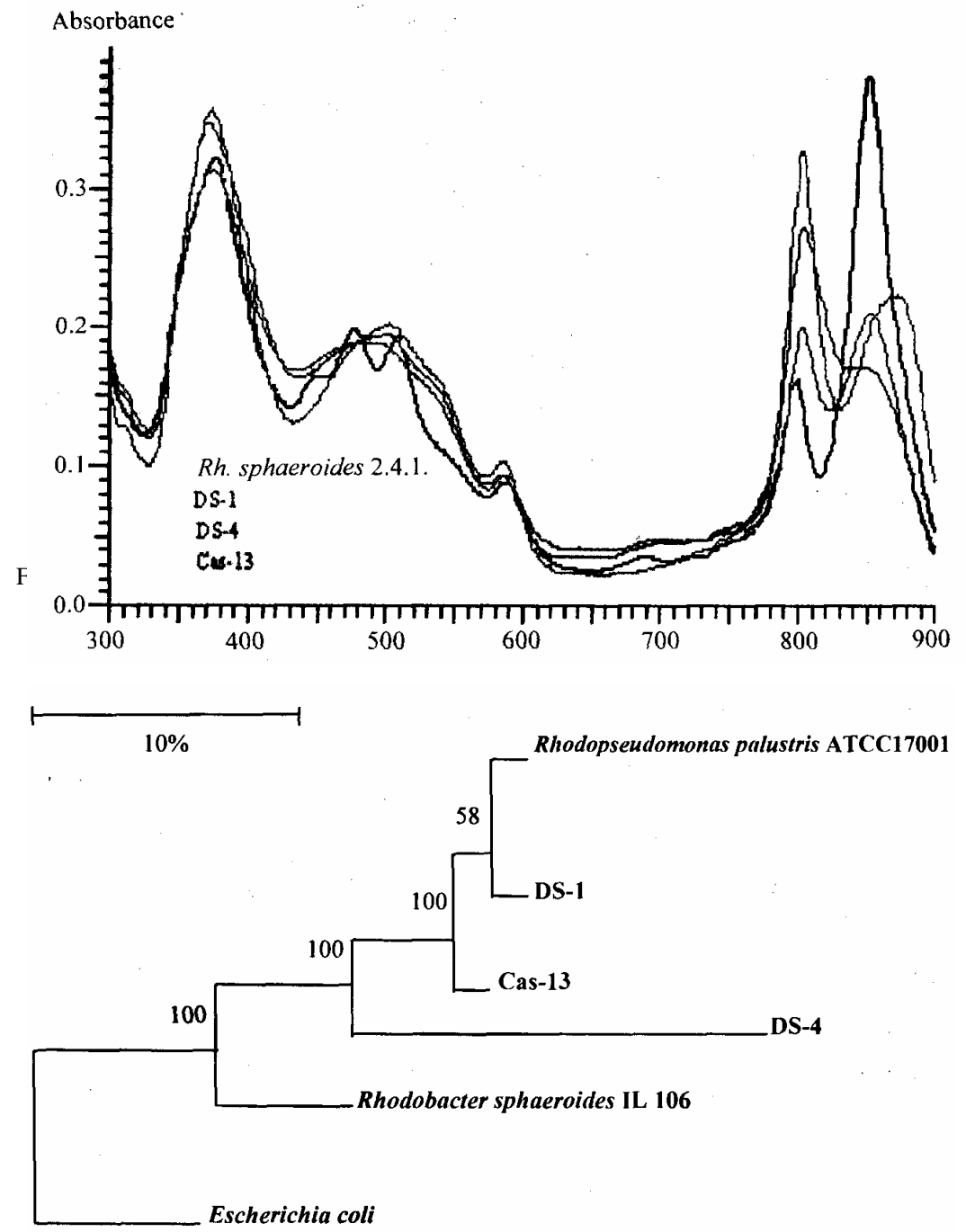

Figure 2. Phylogenetic tree $16 \mathrm{~S}$ rRNA gene sequences. The number at the tree lines represented bootstrap values. 
BIOTROPIA NO. 17, 2001

Table 1. Percent similarity of the DS-1, DS-4, and Cas-13 with other relative members of anoxygenic photosynthetic bacteria.

\begin{tabular}{lccccc}
\hline & $\begin{array}{c}\text { Rb. sphaeroides } \\
\text { IL106 }\end{array}$ & $\begin{array}{c}\text { Rs. palustris } \\
\text { Strain 7 }\end{array}$ & DS-1 & DS-4 & Cas-13 \\
\hline Rb. sphaeroides IL106 & 100 & - & - & - & - \\
Rs. palustris Strain 7 & 86 & 100 & - & - & - \\
DS-1 & 83 & 97 & 100 & - & - \\
DS-4 & 70 & 78 & 78 & 100 & - \\
Cas-13 & 84 & 97 & 99 & 78 & 100 \\
\hline
\end{tabular}

Unlike $R b$. sphaeroides 2.4.1, all of the three isolates were able to metabolize benzoate (Figure 3). Among the members of APB, Rs. palustris is the most common species capable of utilizing benzoate (Harwood and Gibson 1988; Gibson and Gibson 1992; Shoreit and Shaheb 1994).

The ability to grow in the presence of aromatic compounds such as benzoate without vitamins (Figure 3) may suggest that the organisms were able to synthesize their own vitamins. However, supplemented vitamins could increase their potential in metabolizing benzoate. The rate of benzoate utilization for DS-1, DS-4, and Cas-13 were $0.024 \mathrm{mM} /$ hour, $0.02 \mathrm{mM} /$ hour, and $0.03 \mathrm{mM} /$ hour in media with vitamin supplements compared to $0.017 \mathrm{mM} /$ hour, $0.012 \mathrm{mM} /$ hour, and $0.018 \mathrm{mM} /$ hour in media without vitamins. A relatively similar pattern of extended lag phase was observed in growth of the cultures. Time was needed in preparation of producing a number of enzymes.

Carbon availability might affect cell growth. Cell density was observed to be higher in media with benzoate (C7) (Figure 3), followed by succinate (C4) and acetate (C2) (Figure 4). Relatively low cell density of all isolates was shown in $5 \mathrm{mM}$ benzoate with no vitamins. Vitamins were certainly necessary for their metabolic activity. 
Characterization of three benzoate degrading anoxygenic photosynthetic bacteria -Dwi Suryanto et al.
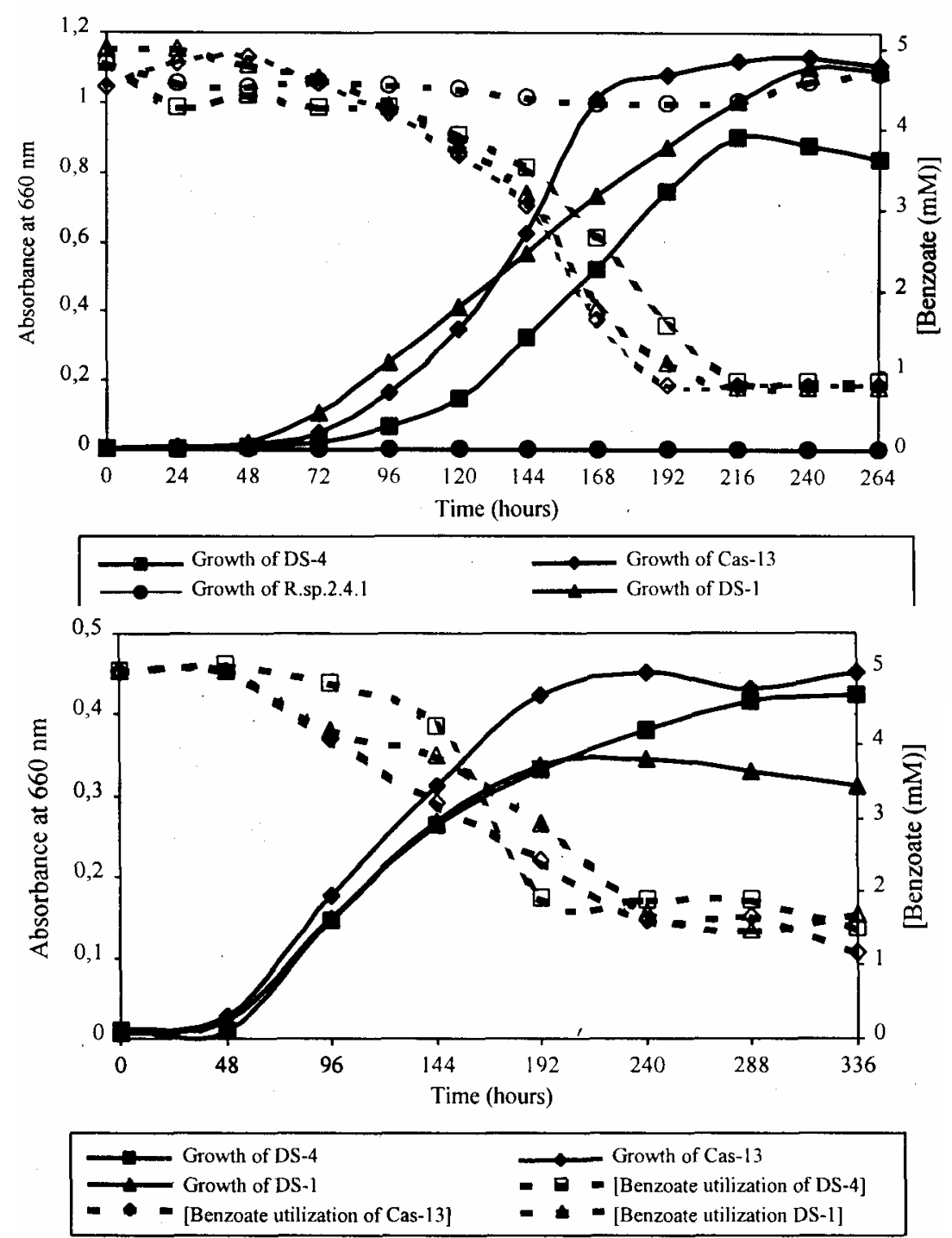

Figure 3. Growht of DS-01, DS-4 and Cas-13 in $5 \mathrm{mM}$ benzoate with vitamins (above) and without vitamins (below). Rb. Sphaeroides 2.4.1. was used as negative control. 

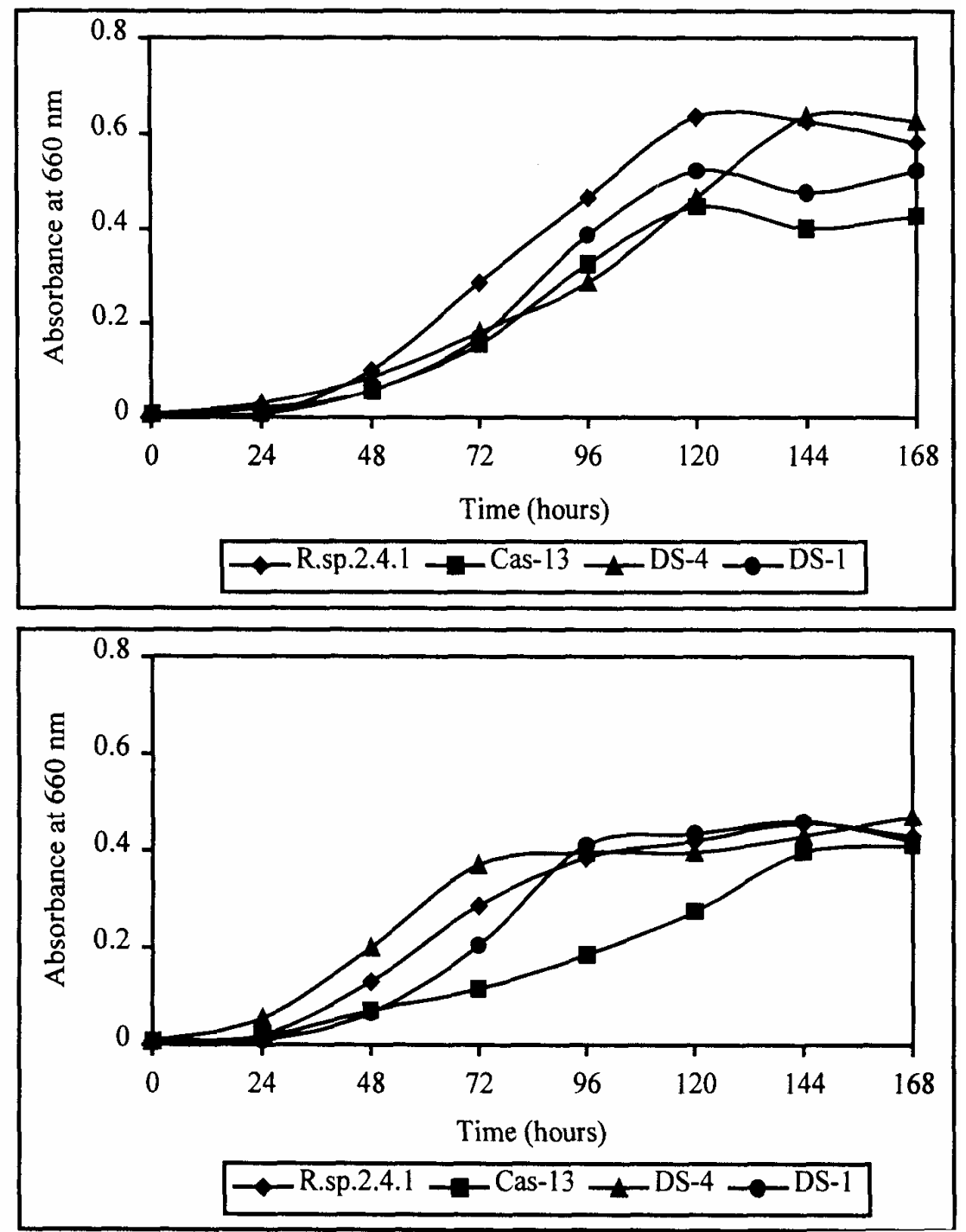

Figure4. Growth of DS-1, DS-4, Cas-4, Cas-13, and R6. Sphaeroides 2.4.1. in $5 \mathrm{mM}$ succinate (above) and $5 \mathrm{mM}$ acetate (below) with vitamins. 
Characterization of three benzoate degrading anoxygenic photosynthetic bacteria -Dwi Suryanto et al.

\section{ACNOWLEDGEMENT}

This research was funded by the Center for Microbial Diversity, Faculty of Science and Mathematics, Bogor Agricultural University, Bogor Indonesia.

\section{REFERENCES}

Blasco, R. and F. Castillo. 1992. Light-dependent degradation of nitrophenols by the phototrophic bacterium Rhodobacter capsulatus E1F1. Appl. Environ. Microbiol. 58: 690-695.

Gibson, K. J and J. Gibson. 1992. Potential early intermediates in anaerobic benzoate degradation by Rhodopseudomonaspalustris. Appl. Environ. Microbiol. 58: 696-698.

Harwood, C. S. and J. Gibson. 1988. Anaerobic and aerobic metabolism of diverse aromatic compounds by the photosynthetic bacterium Rhodopseudomonas palustris. Appl. Environ. Microbiol. 54: 712-717.

Hiraishi, A., K. Muramatsu, and K. Urata. 1995. Characterization of new denitrifying Rhodobacter strains isolated from photosynthetic sludge for wastewater treatment. J. Fermen. Bioengine. 79: 39-44.

Imhoff, J. F. 1995. Taxonomy, phylogeny and general ecology of anoxygenic phototrophic bacteria. In Anoxygenic photosynthetic bacteria. Ed. Blakenship, R.E., M.T. Madigan, and C.E. Bauer. Kluwer Academic Publishers. The Netherlands, p. 1-15.

Kobayashi, M. and M. Kobayashi. 1995. Waste remediation and treatment using anoxygenic photosynthetic bacteria. In Anoxygenic photosynthetic bacteria. Ed. Blakenship, R.E., M.T. Madigan, and C.E. Bauer. Kluwer Academic Publishers. The Netherlands, p. 1269-1282.

Kohring, G., X. Zang, and J. Wiegel. 1989. Anaerobic dechlorination of 2,4-dichlorophenol in freshwater sediments in the presence of sulfate. Appl. Environ. Microbiol. 55: 2735-2737.

Kuo, C. and B.R.S. Genthner. 1996. Effect of added heavy metal ions on biotransformation and biodegradation of 2chlorophenol and 3-chlorobenzoate in anaerobic bacterial consortia. Appl. Environ. Microbiol. 62: 23172323.

Shoreit, A. A. M. and M. S. A. Shaheb. 1994. Utilization of aromatic compounds by phototrophic purple nonsulfur bacteria. Biodegrad. 5: 71-76.

Stackebrandt, E. and F.A. Rainey. 1995. Partial and complete $16 \mathrm{~S}$ rDNA sequences, their use in generation of $16 \mathrm{~S}$ rDNA phylogenetic trees and their implications in molecular ecological studies. In Molecular microbial ecology manual. Ed. Akkermans, A.D.L., J.D. van Elsas, and F.J. De Bruijn. pp. MMEM -3.1.1/1-17.

Wright, G. E. and M. T. Madigan. 1991. Photocatabolism of aromatic compounds by the phototrophic purple bacterium Rhodomicrobium vannielli. Appl. Environ. Microbiol. 57: 2069-2073. 